\title{
ADIÇÃO GRADUAL DA INFORMAÇÃO SOBRE UM PATRIMÔNIO ARQUITETÔNICO: PRODUÇÃO DE MODELOS E DE SENTIDOS
}

\author{
GRADUAL ADDITION OF INFORMATION OVER AN ARCHITECTURAL HERITAGE: \\ PRODUCTION OF MODELS AND SENSES
}

Adriane Borda A. da Silva ${ }^{1}$, Cristiane dos Santos Nunes ${ }^{1}$, Stefani Curth Goulart ${ }^{1}$, Bethina Harter Silva ${ }^{1}$

\section{RESUMO:}

Este estudo relata a estruturação de um método de representação utilizado em um contexto de investigação em arquitetura, especificamente envolvendo a produção em um laboratório de fabricação digital. O método Adição Gradual da Informação - AGI, está dirigido à produção de modelos táteis para apoiar ações culturais inclusivas relativas a um conjunto arquitetônico de interesse histórico e patrimonial da cidade de Pelotas. A partir da teoria da escalada da abstração, de Vilém Flusser, este método é problematizado, observando-se a lógica de associar a variável dimensional das representações envolvidas com os níveis abstracionais exigidos para produzi-las e compreendê-las como meios de comunicação. A dinâmica de estruturação do método, apoiada em processos de co-design, entre universidade e sociedade, atribui sentidos ao uso dos modelos e ao potencial das tecnologias digitais empregadas, promovendo a continuidade na produção e ampliação das narrativas táteis sobre o patrimônio pelotense.

PALAVRAS-CHAVE: Representação; Patrimônio Arquitetônico; Fabricação digital; Modelos táteis; Flusser

\section{ABSTRACT:}

This study reports the structuring of a representation method used in a context of architectural research, involving production in a digital manufacturing lab. The GAl method, an acronym for Gradual Addition of Information, aims at the production of tactile models to support inclusive cultural actions concerning an architectural set of historical and patrimonial interest in the city of Pelotas. From Vilem Flusser's theory of escalation of abstraction, this method is problematized, observing the logic of associating the dimentional variable of the employed means to make and comprehend them. The dynamic of the methods structuring, supported by co-design processes between university and society, assigns meaning to the usage of the models and to the potential of the employed digital technologies, promoting continuity in the production and enlargement of the tactile narratives of Pelotas' patrimony.

KEYWORDS: Representation; Architectural Patrimony; Digital Manufacturing; Tactile Models; Flusser
Fonte de Financiamento: FAPERGS, CNPq e PREC/PROEXT/UFPel

(bolsas de estudantes) Infraestrutura física (máquinas): FINEP, PROEXT, Programa ALFA/CE. Insumos: PROEXT.

Conflito de Interesse: Declara não haver.

Submetido em: 12/04/2020 Aceito em: 08/07/2020

How to cite this article:

BORDA, A. B. A.; NUNES, C. S..; GOULART, S. C.; SILVA, B. H. Adição gradual da informação sobre um patrimônio arquitetônico: produção de modelos e sentidos. Gestão \& Tecnologia de Projetos. São Carlos, v15, n3, p.18-, 2020. https://doi.org/10.11606/gtp.v15i3.168715 


\section{INTRODUÇÃO}

Um conjunto arquitetônico e paisagístico da cidade de Pelotas-RS está reconhecido pelo Instituto do Patrimônio Histórico e Artístico Nacional (IPHAN) como Patrimônio Cultural Brasileiro. Incluem-se neste conjunto uma charqueada, uma chácara, um parque e quatro praças, sendo uma destas a Praça Coronel Pedro Osório. 0 entorno desta Praça preserva diversos edifícios de arquitetura eclética erguidos entre o final do século XIX e início do XX, caracterizando-se como um importante suporte de memória sobre a história da cidade. Situado no centro de Pelotas, este patrimônio remete, por um lado, ao doce lado desta história, ao apogeu econômico da cidade, e, por outro, à cruel maneira de adquiri-lo: apoiado na escravidão. Desta maneira, preserva um cenário produzido por uma dinâmica social que tem sido traduzida, pelo senso comum, com a expressão "entre o sal e o açúcar". Esta expressão também se refere a uma outra materialidade. 0 açúcar era uma das moedas de troca para negociar a carne salgada (charque), a qual sustentava a economia da região a partir da mão de obra escrava. Com isto, a cidade também desenvolveu uma cultura de produção de doces que até hoje perdura, inclusive com certificação de origem para este patrimônio cultural: "doces de Pelotas".

Figura 1: (A) o lugar de uma charqueada; (B) margem do arroio Pelotas; exemplares da arquitetura pelotense de interesse patrimonial nos estilos colonial (C e D) e eclético (E e F)

Fonte: Acervo da Secretaria de Cultura da Prefeitura Municipal de Pelotas
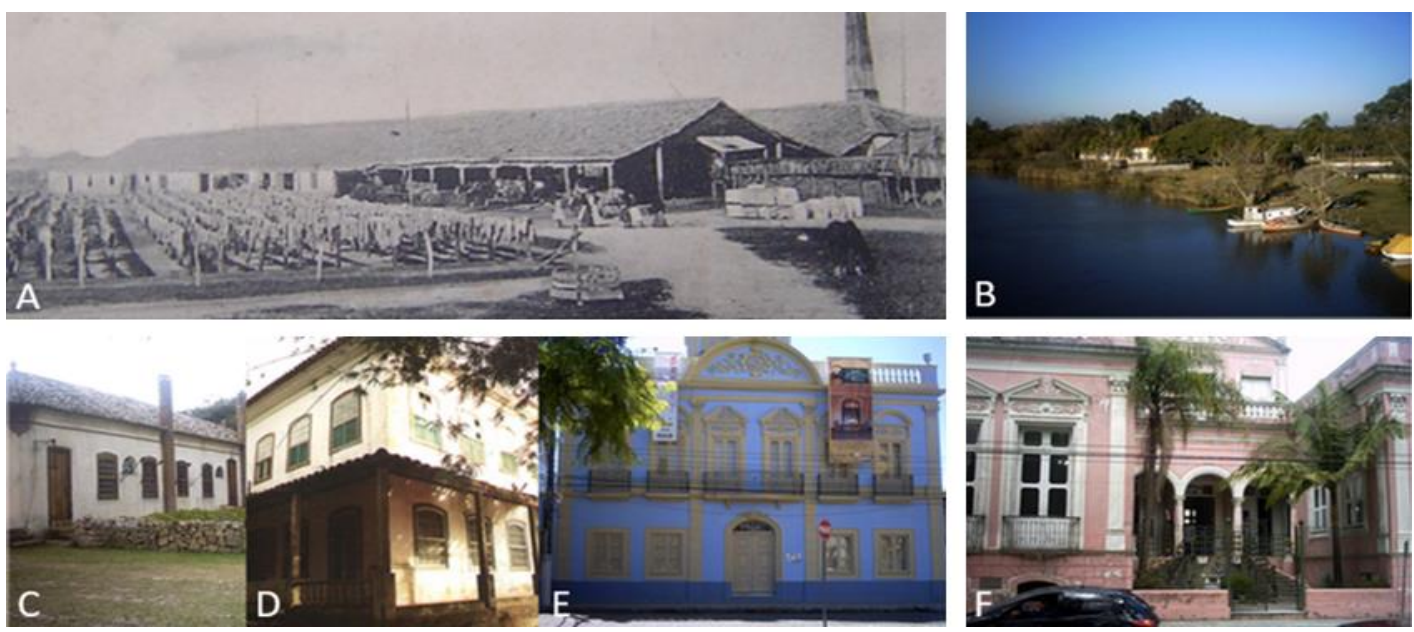

A arquitetura do entorno da Praça Coronel Pedro Osório permite reconstruir na memória, quando contraposta à arquitetura que abrigava a indústria saladeril, o momento em que existia o propósito de afirmar o poder econômico dos proprietários dos casarões, que eram os próprios charqueadores. Estes construíram um cenário urbano, aos moldes europeus da época, que contrastava totalmente à insalubridade daquele ambiente industrial. 0 conjunto de fotografias da Figura 1 facilita imaginar estes dois cenários. As charqueadas pelotenses (A) se estabeleceram ao longo do Arroio Pelotas (B), na época, referido como "rio vermelho", devido às manchas de sangue decorrentes dos dejetos da matança do gado para a produção do charque (carne salgada e exposta ao sol nos varais). Havendo uma sazonalidade para esta produção (época de engorde do gado), as mesmas instalações abrigavam as olarias, mantendo assim ativa a mão de obra escrava durante todo o ano. A zona urbana se constituiu longe desta realidade de exploração humana. Exploração que sustentava o luxo e opulência dos charqueadores. Em um primeiro momento, a arquitetura no estilo colonial abrigava tanto as sedes industriais (C e D) como as casas assobradadas do centro da cidade. Logo, muitas delas adquiriram novos elementos, para configurar, com outras novas construções, um conjunto que retratasse a modernidade daquele momento. Isto está demonstrado ao observar, lado a lado: construções sem porão alto e com beiral (estilo colonial) (D); construções sem porão alto e com platibandas e balaústres (readequadas para a linguagem do ecletismo) (E); e, aquelas já projetadas sob a linguagem do ecletismo, com porão alto, platibandas e balaustradas (F). 
Todo este discurso acompanha o roteiro turístico da cidade, contextualizando assim os elementos preservados da paisagem urbana, como alguns monumentos, arquiteturas e seus ornamentos. Os estudos históricos de Gutierrez $(1993,2010)$ sistematizaram a história do ciclo do charque, o qual compreendeu o período de 1777 até 1930 . 0 tipo de edificação, que sediava esta indústria, variava entre o padrão português em fita, com pátio interno ou ainda assobradado, sem a abundância de adornos figurativos e em ferro, como já exemplificado na Figura 1 (C e D). Posteriormente, estes adornos passaram a caracterizar os edifícios públicos e os casarões urbanos.

Especialmente o patrimônio arquitetônico do entorno da Praça Coronel Pedro Osório é rico em elementos que compõem narrativas diversas. Em particular, os estudos de Santos (2007) contribuem para a compreensão destas narrativas, tratando de analisar o significado de cada ornamento destas edificações. Tal ornamentação compõe uma linguagem, própria de um ecletismo histórico, como caracterizado pelo referido autor, percebida em diferentes graus de erudição, em termos de correspondência com aquela linguagem importada da Europa. Muitos dos edifícios, a partir destas ornamentações explicitam, externa e internamente, seus usos e propósitos. A partir da disponibilização de catálogos, os elementos ornamentais eram adquiridos, atentando para indicar o poder do proprietário da edificação. Quanto mais exclusivos eram estes adornos, maior poder era demonstrado, podendo inclusive contar com artífices particulares e especializados, sem lançar mão de elementos de catálogos.

Este tipo de caso pode ser ilustrado com o conjunto de adornos do Casarão 8 (Figura 2, (A)). Esta edificação, juntamente com os outros dois casarões ecléticos da Figura 1 (E e F), compõe a testada de um quarteirão, totalmente preservada, do entorno da referida praça. Os elementos decorativos, especialmente os estuques dos tetos, constituem uma narrativa que permite identificar a função original de cada um dos cômodos do corpo principal da "casa do conselheiro". Assim era tratada esta casa, em sua época, por habitar ali Francisco Antunes Maciel, conselheiro do Imperador D. Pedro II, conforme descrito em Michelon (2016). 0 teto da sala de jantar, como pode ser observado na Figura 2 (B), exemplifica tal propósito. A representação refere-se a uma mesa posta, induzindo a uma disposição do mobiliário e até mesmo contando sobre os hábitos alimentares: estão representadas figuras relativas a diversos animais de caça, frutas e legumes, além de pratos e talheres como ilustra o detalhe (C). Deve-se ter em conta que esta narrativa é acessível, naturalmente, às pessoas videntes.

A possibilidade de apropriação destes edifícios como suportes de memória, por qualquer pessoa, está seguramente associada a um conjunto de experiências, envolvendo cada um dos sentidos. Referindo-se à percepção da paisagem urbana, o sentido da visão assume um papel mais importante ainda, sendo necessário proporcionar meios para que pessoas com deficiências visuais possam ser incluídas neste processo cultural. Com este propósito, o presente estudo relata o processo de estruturação de um método de representação, que está sendo utilizado para a produção de modelos táteis relativos ao patrimônio arquitetônico pelotense. Esta produção insere-se em um contexto de investigação em arquitetura, no âmbito de um laboratório de fabricação digital, junto à Faculdade de Arquitetura e Urbanismo da Universidade Federal de Pelotas.
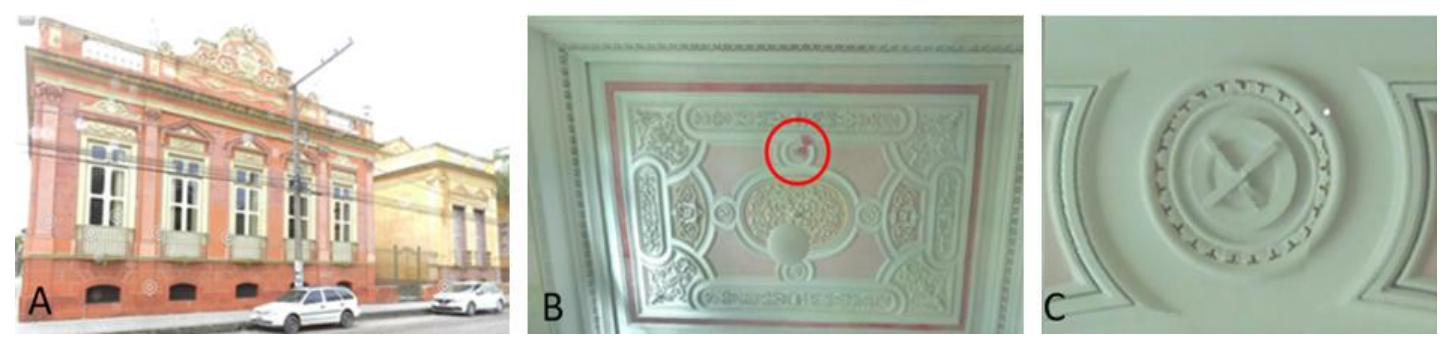

Figura 2: (A) fachada do Casarão 8; (B) decoração do teto da sala de jantar; (C) detalhe ressaltado sobre a imagem, garfo e faca cruzados sobre um prato Fonte: autoras a partir da nuvem de pontos 


\section{OS REFERENCIAIS TEÓRICOS QUE APOIAM A PRODUÇÃO}

As maquetes (modelos físicos) de arquitetura possibilitam ampliar a percepção da forma das edificações e do contexto urbano para qualquer pessoa, independentemente de suas capacidades visuais. Este potencial das maquetes é destacado por Pereira et al. (2017), um estudo que traz um aporte científico diferenciado, tendo, como autor principal, um profissional experiente em arquitetura e que se constituiu pesquisador doutor, também na área de arquitetura, após agregar a experiência de perda total de seu sentido de visão. Há uma marcada crítica ao domínio da visão sobre outras modalidades sensoriais junto à prática de arquitetura, em sintonia com as reflexões de Pallasmaa (2011), que já enfatizava a necessidade de a própria arquitetura provocar a experiência multissensorial. Ambos os estudos alertam para a tendência ocularcentrista na arquitetura, incrementada pelo uso de novas tecnologias. Entretanto, para Juhani Pallasmaa, "embora as novas tecnologias tenham reforçado a hegemonia da visão, elas também podem ajudar a reequilibrar as esferas dos sentidos" (PALLASMAA, 2011, p. 34). No âmbito do presente estudo, este mesmo tipo de reflexão é direcionado ao questionamento sobre como melhor explorar as tecnologias de fabricação digital para traduzir/produzir as multissensorialidades que o patrimônio arquitetônico tratado é capaz de ativar.

Por outra parte, tratando-se de um contexto formativo de arquitetura, os preceitos do Desenho Universal, nos termos de Ornstein (2010), guiam a problematização das representações táteis produzidas. Consideram-se, assim, os sete princípios do Desenho Universal, a saber: I - uso equitativo; II - uso flexível; III - uso simples e intuitivo; IV - informação de fácil percepção; V segurança; VI - esforço físico mínimo; VII - dimensionamento para acesso e uso abrangente (ORNSTEIN, 2010, p. 15-21). Adentrando-se neste campo, os modelos táteis passaram a ser compreendidos como um tipo de recurso assistivo, a partir das categorias apresentadas em Cook e Polgar (2008). Estes modelos podem, então, ser utilizados como um equipamento para auxiliar na sensorialidade de diferentes tipos de deficiência, como um sistema de comunicação alternativa ou, ainda, como uma tecnologia assistiva para apoiar ações educativas ou profissionais.

A produção destes recursos, empregando tecnologias de fabricação digital por impressão 3D e corte a laser, parte da interpretação da atividade de representar a geometria da forma como meio de construção de conhecimento, considerando-se que "conhecer é modificar, transformar o objeto, e compreender o resultado dessa transformação" (PIAGET, 2002, p. 1). Toda esta interação com o objeto, para ser representado, estimula a investigação sobre a especificidade formal e construtiva da arquitetura envolvida, exigindo a compreensão de uma lógica associativa ao contexto histórico, social e cultural do momento em que foi produzida. Com isto, este processo de representação promove a construção de narrativas para serem agregadas ao uso dos modelos táteis, reforçando-os como suportes de memória, ativadores de sentidos, agregando assim maior significado a este tipo de recurso assistivo.

Todo o processo de produção dos recursos assistivos está sendo realizado juntamente a pessoas com cegueira ou baixa visão através de atividades extensionistas, nas quais os modelos produzidos são avaliados quanto a sua capacidade de comunicação. Dessa maneira, apoia-se no conceito de co-design, nos termos de Pereira et al. (2017), tendo o usuário como ator no processo de projeto, ao invés de ser somente representado por um especialista. Esse processo colaborativo vai ao encontro do discurso de Freire (2013), o qual destaca que ações de extensão devem promover a participação ativa dos integrantes do grupo para a construção do conhecimento.

Junto a estas reflexões adicionam-se também os referenciais advindos da área da comunicação. Especificamente, as representações produzidas estão sendo problematizadas utilizando-se da teoria da escalada da abstração de Vilém Flusser (1998). Esta teoria confere dimensões aos 
meios de comunicação inversamente proporcionais ao grau de abstração exigido para a sua compreensão: parte do tridimensional, referindo-se àqueles que se valem diretamente da experiência com o objeto físico, envolvendo o corpo em seus cinco sentidos e por tanto com menor grau de abstração em relação aos demais; avança para o bidimensional, utilizando-se da imagem do objeto, quando produzida por meios tradicionais (desenho); caracteriza o unidimensional, dirigindo-se à escrita (códigos de linguagem); e por fim anuncia o nulodimensional. Esta adimensionalidade corresponde então ao maior grau de abstração, atribuída ao que caracteriza como imagens técnicas, produzidas por aparelhos e passíveis de serem computáveis, de serem transformadas em número. Esta leitura realizada por Flusser, para compreender a própria história da humanidade, é aqui transposta para provocar um exercício reflexivo, utilizada minimamente ante sua complexidade. Sob esta lógica dimensional/abstracional, realiza-se uma reflexão sobre todos os meios de comunicação que envolvem a estruturação do método utilizado.

De antemão, este método transita entre diferentes "dimensões" para representar o patrimônio referido desde: as edificações, em concreto, que compõem a paisagem, envolvendo todos os sentidos (tridimensional); as suas imagens (bidimensionais); aos textos que as descrevem (unidimensionais); às imagens técnicas computacionais, produzidas pelos aparelhos, necessárias para a estruturação da narrativa tangível desta paisagem urbana (nulodimensionais), e por fim, aos modelos físicos em escala adequada ao sentido do tato, os quais podem ser percebidos por todas as pessoas, retornando à tridimensionalidade.

Com este trabalho, buscou-se avançar em todo este processo reflexivo, a partir da teoria da escalada da abstração, para potencializar o método da Adição Gradual da Informação, como tem sido referido o método de produção de modelos táteis como recursos assistivos, junto ao contexto em que está sendo estruturado.

\section{O MÉTODO DE PRODUÇÃO DOS MODELOS}

A delimitação do método da Adição Gradual da Informação, AGI, advém de uma trajetória prévia, registrada em Borda et al. (2012) e Dalla Vecchia et al. (2015). Em 2012, esta produção esteve dirigida à tentativa de tradução da geometria da imagem fotográfica (bidimensional) para um meio tátil. Em 2015, o método já esteve dirigido à comunicação tátil da geometria da própria arquitetura, na escala do detalhe e do edifício. Em 2018, a aplicação do método já havia avançado para a escala urbana e foi descrito em Borda et al. (2018), texto aqui ampliado. Para a aplicação do método a uma paisagem urbana, partiu-se de um apoio pré-existente a roteiros turísticos, sobre o entorno da Praça Coronel Pedro Osório, disponibilizado por instituições de caráter público (Prefeitura e Universidade). Logo, tratou-se de problematizar cada etapa de projeto e da fabricação dos modelos táteis, sob as abordagens teóricas anteriormente apresentadas. Sendo assim, estabeleceu-se um processo de co-design, sob os preceitos do Desenho Universal, investindo-se na formação dos pesquisadores/estudantes para as ações extensionistas, para a apropriação das tecnologias de representação e fabricação digital e, sobretudo, para a compreensão do significado social e cultural dos recursos assistivos. 0 método empregado trata de definir, de acordo com a especificidade de cada elemento representado, o número de camadas de informação a serem geradas. Estas camadas referemse às diferentes escalas de representação, que passam a constituir uma narrativa tátil, para ampliar a percepção desde o todo da paisagem urbana aos detalhes das edificações.

Esta narrativa tátil vem sendo produzida por estudantes da Faculdade de Arquitetura e Urbanismo, FAUrb, da Universidade Federal de Pelotas, UFPel, no âmbito da pesquisa, do ensino e da extensão, contemplando tanto interesses formativos quanto demandas institucionais. A demanda por recursos assistivos de apoio a um roteiro cultural e turístico tem 
sido apontada pelas Secretarias Municipais de Cultura e de Desenvolvimento e Turismo de Pelotas e pela própria UFPel, para uso em ambientes culturais de sua responsabilidade. Neste caso, dois dos museus universitários se situam em edificações, de interesse patrimonial, do entorno da Praça Coronel Pedro Osório: o Museu do Doce e o Museu de Ciências Naturais Carlos Ritter. Com isto, os recursos assistivos que estão sendo produzidos já estão tendo um espaço expositivo para serem acessados e testados de maneira aberta, em diálogo com a sociedade, permitindo estabelecer a indissociabilidade entre ensino, pesquisa e extensão.

\section{A INFRAESTRUTURA PRÉ-EXISTENTE}

O turismo tem acompanhado a evolução das tecnologias de informação e comunicação modernizando suas estruturas e qualificando seus agentes. Serviços on-line têm facilitado aos turistas acessar a informação sobre os pontos de interesse em qualquer momento e lugar. Estas possibilidades remetem ao conceito de turismo ubíquo. Conforme Silva et al. (2014), este conceito é empregado por guias eletrônicos de turismo, quando possibilitam através de georreferenciamento e de dispositivos móveis, como tablets e smartphones, fornecer informações contextuais, de maneira interativa e instantânea, do local para o usuário. Certamente, muitos dos roteiros turísticos realizados na Praça Coronel Pedro Osório devem estar sendo dirigidos sob a consulta, pelo próprio turista, de sites especializados, incluindo aquele organizado pela Prefeitura Municipal de Pelotas. Alguns deles avançam também em termos de acessibilidade à informação, disponibilizando recursos de áudio e de tradução para língua de sinais. Além disto, agentes públicos e privados, promovem passeios acompanhados de um discurso oral, por vezes contando com folders específicos sobre o centro histórico de Pelotas, o qual tem como ponto focal a referida praça. Partiu-se, assim, de roteiros já estruturados. Em particular, adotou-se um folder, produzido em 1994 pelo Núcleo de Estudos de Arquitetura Brasileira, NEAB/FAUrb/UFPel. Este material inclui informações textuais e ilustradas, exemplificado na Figura 3, sobre o entorno da praça. A numeração, indicada sobre o mapa, localiza as edificações de interesse patrimonial e remete aos desenhos de fachadas, aos dados históricos e às características arquitetônicas principais de cada uma delas, informações sistematizadas a partir de projetos de investigação desenvolvidos pelo NEAB. No folder está uma descrição suscinta, exemplificada, na mesma imagem, pelo caso da sede da Prefeitura Municipal de Pelotas.

Figura 3: llustrações do folder sobre a Praça Coronel Pedro Osório: capa; mapa do entorno; exemplo de descrição de uma edificação

Fonte: Acervo do NEAB (Núcleo de Estudos de Arquitetura Brasileira), FAUrb, UFPel
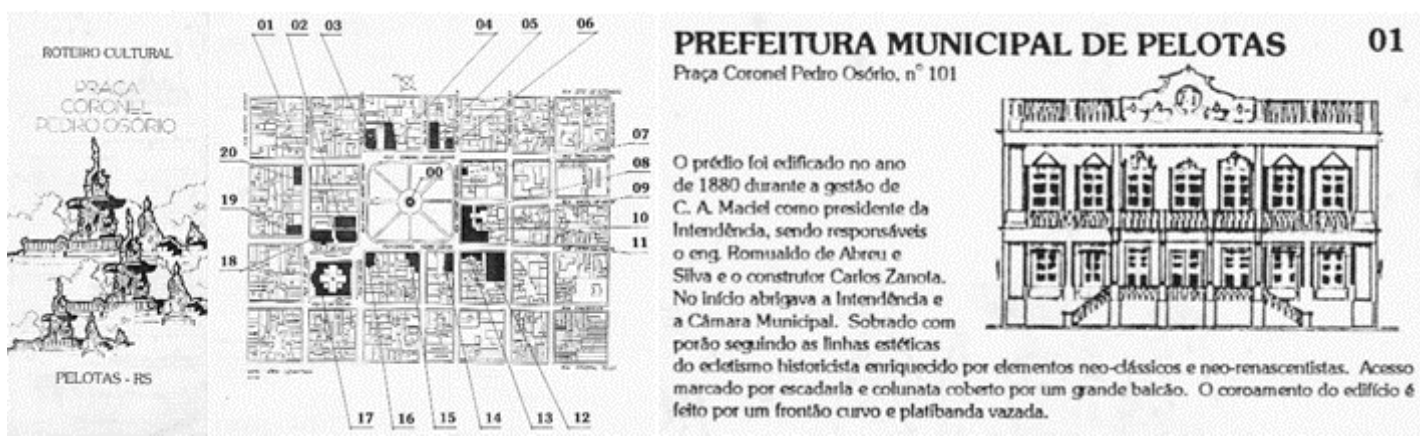

Os modelos digitais deste entorno urbano foram executados a partir das seguintes fontes: documentação arquitetônica disponibilizada pelo NEAB/FAUrb/UFPel e pela Prefeitura Municipal de Pelotas (PMP); imagens obtidas no Google Maps (https://www.google.com.br/maps/), através da ferramenta Street View; imagem em alta resolução da área, disponibilizada pela PMP; mapa vetorizado do lugar com a marcação dos lotes; modelos geométricos (digitais) disponíveis no Armazém 3D (https://3dwarehouse.sketchup.com), relativos à produção do Projeto MODELA Pelotas, conforme consta no registro junto a esta plataforma de modelos. Contou-se também com dados 
obtidos por meio de tecnologias de fotogrametria digital e escaneamento 3D a laser, para uma das edificações, caso registrado em Borda et al. $(2016,2017)$. Desta maneira, as fontes de dados foram diversas, confrontando-se as informações para avançar em termos de precisão para a representação. Entretanto, este aspecto (precisão de medidas) não chega a adquirir relevância frente às escalas de representação, aos objetivos e às tecnologias empregadas. Conforme Pereira et al. (2017), modelos táteis precisam ter formas simples, ampliando-se detalhes relevantes e eliminando-se aqueles que produzem ruídos à percepção tátil. Com isto, mesmo partindo-se de representações anteriormente executadas, sob outros propósitos de representação, foi necessária uma remodelagem, conforme o caso e a escala. A Figura 4 ilustra um processo de simplificação de fachada. A imagem (A) refere-se a uma fotografia retificada da fachada principal do Casarão da Família Assumpção, edificado em 1887. Esta fotografia foi utilizada como textura sobre um modelo digital simplificado, o qual não contém a geometria dos elementos ornamentais. Este tipo de modelo facilita a sua disponibilização na plataforma Google Earth em 3D, sendo possível informar, visualmente, a complexidade formal, sem sobrecarregar o modelo digital. A imagem (B) refere-se ao modelo da mesma fachada, produzido para ser impresso em 3D, na escala 1:75, e representar, de maneira simplificada, a geometria dos ornamentos. Este modelo seguiu as orientações dos colaboradores com deficiência visual, de controle do grau de rugosidade para ser possível perceber cada elemento individualmente pela ponta dos dedos. A imagem (C) mostra uma simplificação maior da fachada para a impressão na escala da maquete da Praça (1:500), com o propósito de informar tipologias das edificações e proporções entre elas, para a percepção da configuração de todo o entorno em questão.

O critério para a seleção dos elementos a serem representados neste processo de simplificação da geometria das fachadas foi conduzido essencialmente pelos textos relativos às características arquitetônicas que particularizam cada edificação, constantes no folder de referência. Para o caso do Casarão relativo às fachadas da Figura 4, por exemplo, a descrição textual ressalta o tipo de edificação e a situação em relação ao quarteirão: "casarão de esquina e de partido de corredor lateral". Esta localização pode ser observada junto à representação de toda a praça e seu entorno, na Figura 5, cujo formato da edificação parece a letra E refletida, situada no canto superior esquerdo da fotografia.
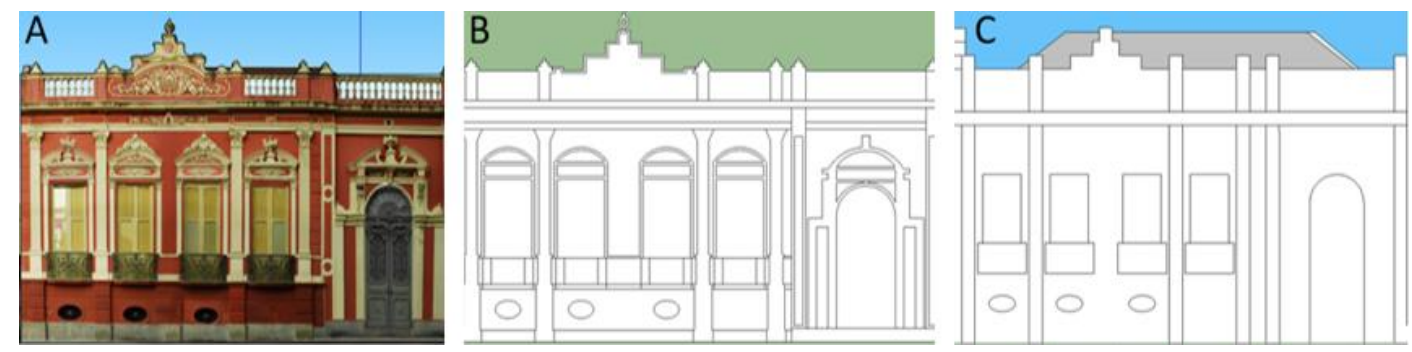

Figura 4: Simplificações de uma fachada: A) para a disponibilização no Armazém 3D (fotografia retificada como textura); B) para impressão 3D, na escala 1:75; C) idem, na 1:500

Fonte: Borda et al. 2018
Prosseguindo sobre a narrativa da mesma fachada, o modelo tátil enfatiza o que está destacado textualmente, sobre a presença de um porão alto, habitável e com aberturas em formato elíptico, denominadas gateiras. 0 texto também descreve a existência de pilastras, marcando o ritmo da fachada, assim como outras volumetrias representadas para ilustrar a seguinte descrição: "[...] corpo com vãos de sacada de púlpito em ferro, esquadrias com bandeira de verga reta e com ornamentos, de massa, na parte superior [...]". Todos os adornos, incluindo os dos elementos que sustentam o coroamento da fachada, aparecem particularizados na escala de 1:75. Nesta escala promove-se a tradução tátil do seguinte texto "[...] cimalha com cornija, 
friso e arquitrave profusamente trabalhada", elementos que na escala de 1:500 fundem-se em uma única saliência.

A maquete da paisagem urbana é adotada como dispositivo inicial das narrativas de cada edificação, informando sobre os parâmetros de localização, orientação, forma e proporção em relação a todo o entorno. Observa-se, neste conjunto na escala 1:500, o propósito de diferenciar os edifícios pelos materiais e tecnologias de fabricação empregados: os inventariados ou tombados, relativos à arquitetura eclética, estão sendo produzidos em PLA (polímero poliácido láctico) branco, a partir da tecnologia de impressão 3D (método aditivo, por deposição de camadas de PLA fundido). 0 acabamento opaco permite a compreensão da forma por pessoas com baixa visão; as demais edificações estão sendo produzidas em MDF (placa de fibra de média densidade), a partir do corte a laser. Até o momento estas representações referem-se apenas ao sólido envolvente das edificações, sem adicionar nenhum detalhe de fachada. Os modelos digitais foram produzidos a partir da extrusão dos polígonos dos lotes de um mapa vetorizado, disponibilizado pela PMP, respeitando-se as respectivas alturas das edificações. Nota-se ainda que a base da maquete está constituída por uma imagem aérea, em alta resolução, da Praça e de seu entorno. Com esta imagem busca-se facilitar a compreensão de pessoas sem deficiência visual. 0 contraste de materiais também facilita a identificação e diferenciação dos edifícios históricos por pessoas com baixa visão.

Figura 5: Fotografia da maquete tátil da Praça Coronel Pedro Osório e de seu entorno

Fonte: Borda et al. 2018

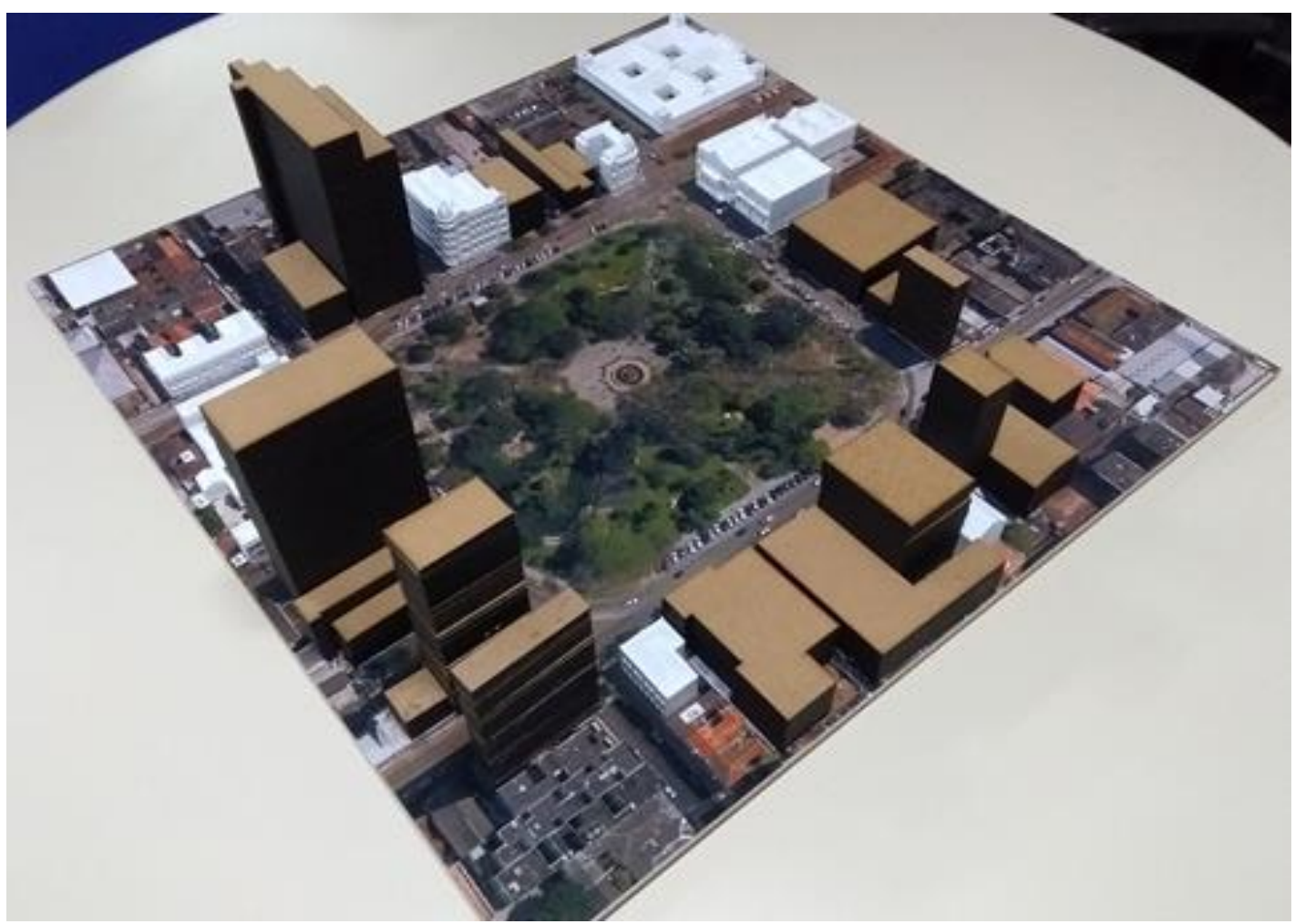

\section{ADIÇÃO GRADUAL DA INFORMAÇÃO: MÉTODO APLICADO}

Dentre as 20 edificações destacadas, do entorno da praça, junto ao folder de referência, 13 delas foram representadas em sua volumetria externa na escala 1:500 por impressão 3D. A aplicação do método AGI, até então, foi realizada em 8 destas 13 edificações, avançando-se assim para a representação de fachadas principais, na 1:75, como exemplificado na Figura 4. A particularização destas fachadas, tem a intenção de provocar a percepção tátil sobre as diferenças de linguagem das composições arquitetônicas, por destacar as identidades de cada edifício, já expressas, pelo folder, na linguagem textual e do desenho. A representação, em cinco 
escalas, variando de 1:500 a 1:10, já apoia uma narrativa tátil sobre a cúpula do Grande Hotel, processo descrito em Dalla Vecchia et al. (2015). Esta cúpula se sobressai no entorno da praça, coroando a edificação de maior porte em altura para a época, concluída em 1928. Além disto, o método tem sido aplicado de maneira mais sistemática junto ao Casarão 8 (Museu do Doce), conforme descrito em Borda et al. (2016) e Borda (2017), contando-se com uma representação precisa, por nuvem de pontos, obtida pelo escaneamento a laser do edifício, interna e externamente. Este edifício oportuniza visitas públicas, tendo assim um suporte para o acervo dos recursos assistivos juntamente com a infraestrutura de mediação. Existem, para este caso, narrativas que se apoiam desde a escala urbana na 1:500 até à escala de 1:1, usada, por exemplo, para descrever uma figura do estuque do teto deste casarão.

A tabela 1 registra o estágio de aplicação do método AGI. Valores quantitativos, relativos ao número de estudantes e de horas envolvidos, ao longo da produção, são imprecisos, especialmente por compreender uma diversidade de perfis de habilidades com as tecnologias de representação, do início da graduação à pós-graduação.

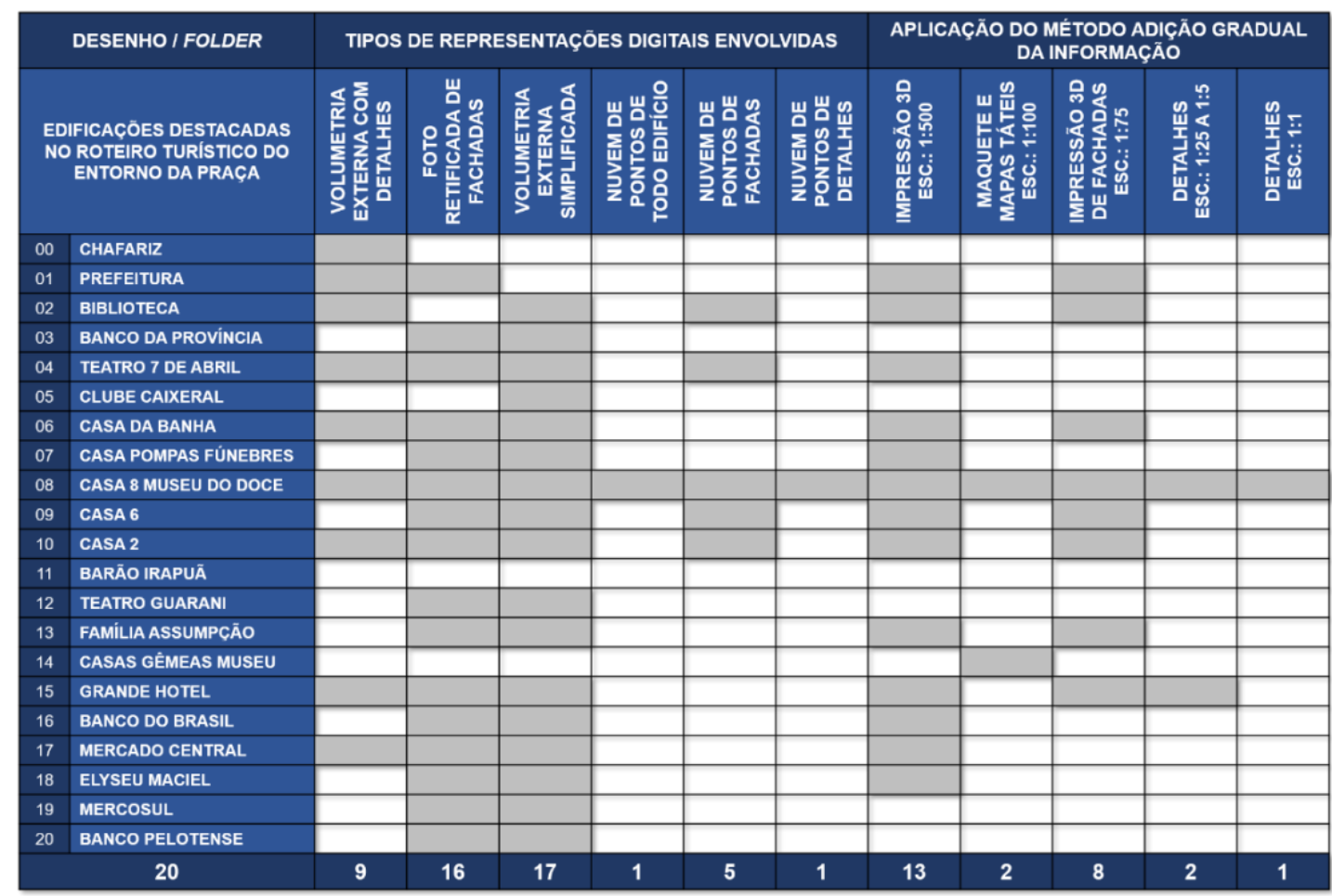

As sistematizações em relação à eficácia dos recursos, tem envolvido toda a equipe de codesign, dependentes assim de observações advindas de diferentes áreas, como por exemplo, terapia ocupacional, museologia, turismo, história e teoria da arquitetura, gestores das instituições envolvidas, mediadores dos museus, usuários em geral. Estas reflexões estão em processo, dependentes da contínua revisão dos recursos, a partir da experiência em cada ação, sendo estes ajustados, seja na forma ou em número de camadas, para estruturar e ampliar as narrativas táteis. Quanto às reflexões advindas de usuários com deficiência visual, contou-se, em um primeiro momento, com a participação de um estudante de Museologia, com limitação total do sentido de visão, porém com memória visual recente, inclusive tendo um repertório necessário para o reconhecimento da arquitetura representada. E, ao longo do processo, conta-se com a parceria da Escola Louis Braille, por meio do uso dos recursos por estudantes, cujos perfis abarcam uma grande diversidade em termos de: grau de deficiência visual, idade, gênero, nível de escolaridade e capacidade cognitiva. Neste caso o uso tem sido realizado de
Tabela 1: Registro do estágio de aplicação do método AGI, nas edificações destacadas no folder de referência, relativo à Praça Coronel Pedro Osório, Pelotas, RS

Fonte: Produzido pelas 
maneira coletiva, envolvendo um mínimo de vinte pessoas. As imagens da Figura 6 ilustram um destes momentos de experimentação, em junho de 2018, junto a uma turma de adultos da escola citada. Demonstra-se a flexibilidade dos recursos em permitir destacar cada uma das representações na escala 1:500 (A) para serem totalmente manuseadas e associadas às representações das fachadas ou elementos que complementam a informação sobre estas edificações em outra escala (B e C). A cada momento de uso são registradas, por fotografias e por vídeos, as percepções tanto por parte da equipe envolvida como por parte dos usuários. Desta maneira, busca-se compreender como cada uma das camadas de informação, e em seu conjunto, acionam um processo de educação patrimonial. Mesmo sem ainda ter havido uma sistematização dos registros fotográficos e de vídeo, estes evidenciam a expressão de afetos de todos os envolvidos e o uso efetivo destes recursos como suportes de memória. Dentre estas evidências, pode-se citar o caso de uma criança, do grupo da Escola referida, com deficiência visual total, que, de maneira espontânea, em um momento imediatamente após a experiência com a maquete, tentou reproduzir, utilizando-se de peças de montar, um dos modelos experenciados.

Outro caso, que evidencia a produção de afetos, refere-se a um estudante também da mesma escola, já idoso e com cegueira total recente. Ao visitar o Museu do Doce e tocar nos modelos que facilitam a compreensão da forma dos elementos decorativos dos estuques dos tetos expressou, com lágrimas nos olhos: “Estou vendo mais do que quando eu tinha visão!". Este estudante declarou que frequentava aquele casarão quando ali se situava uma repartição da Prefeitura e que nunca havia olhado para o teto. E complementou: "isto sempre foi bonito assim?".

A aplicação do método AGI exige o trânsito entre as diferentes escalas, havendo assim a necessidade de um investimento contínuo na produção de conhecimento para sustentar o discurso sobre cada camada de informação gerada. Isto tem provocado avançar em estudos como os desenvolvidos em Santos (2007), os quais objetivam decifrar as narrativas constituídas pelas arquiteturas envolvidas. A particularização de cada um dos elementos decorativos exige agregar vocabulário e interpretar as representações, compreendendo suas relações para a estruturação de tais narrativas.

Figura 6: Registro fotográfico do uso dos modelos táteis junto a uma ação realizada na Escola Louis Braille de Pelotas em junho/2018

Fonte: Borda et al. 2018
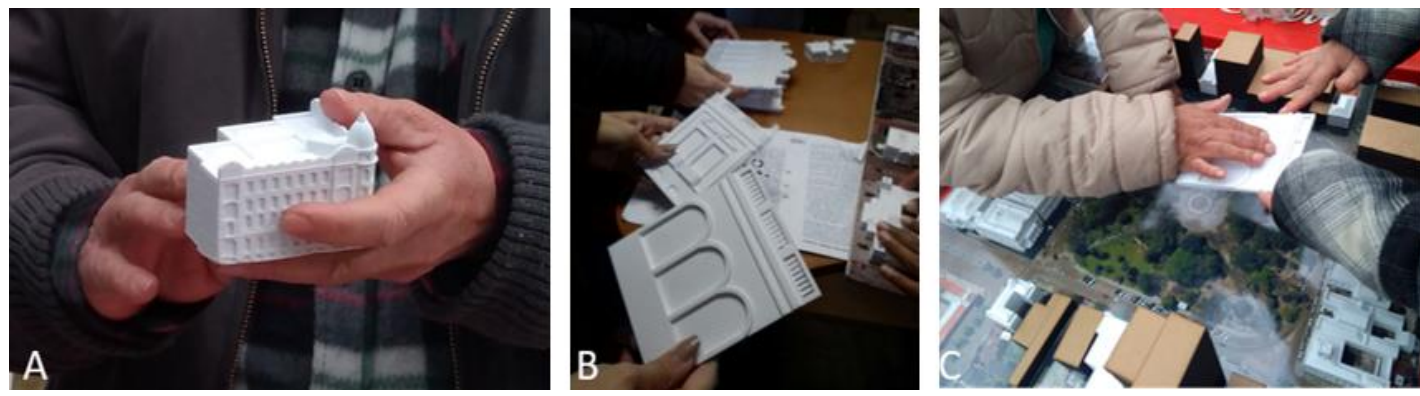

Todo este esforço constitui as atividades formativas que integram saberes próprios da prática de arquitetura. Para cada uma das edificações e em particular para aquelas que estão de portas abertas para a recepção cultural e de educação patrimonial, como a sede dos museus universitários já mencionados, faz-se oportuno investir na produção de novas camadas de informação, envolvendo diferentes abordagens, escalas e tecnologias. Esta diversidade facilita contemplar um desenho universal. 
Nesta direção, tem-se adicionado camadas de informação mais próprias de um fazer arquitetônico, e que também têm sido compartilhadas e difundidas nestes espaços culturais em que esta produção está tendo a oportunidade de ser validada. Trata-se de saberes específicos da geometria gráfica que sustentam a prática de organização formal constituída ao longo da história da arquitetura. Como exemplificado nas imagens da Figura 7, por meio de traçados, são investigados os lugares geométricos específicos para a posição de cada elemento, desde a escala do detalhe (B) a do edifício (C). Estes lugares, subjacentes às composições, são configurados como camadas de informação sobre as representações físicas. Para isto, o uso de tecnologias, como o escaneamento a laser (caso da imagem $\mathrm{C}$ ) e a fotogrametria digital (caso da imagem A), tem sido fundamental, pois as hipóteses são elaboradas sobre representações precisas.
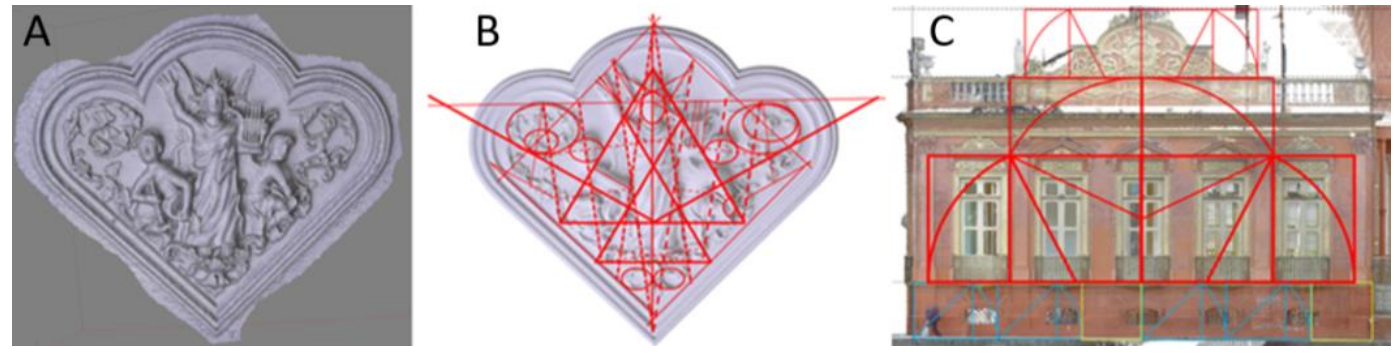

Figura 7: Estudos de geometria gráfica sobre nuvens de pontos dos elementos do patrimônio: um detalhe do estuque e da fachada do Casarão 8

Fonte: Borda (2017)
A Figura 8 ilustra uma narrativa que objetiva conectar a escala urbana a de um edifício em particular. 0 caso exemplificado, indicado sobre a escala urbana (A), e ainda representado de maneira simplificada, refere-se às "casas gêmeas" (B), como reconhecidas pelo senso comum pelotense, situadas em uma das esquinas do entorno da Praça. A parte exatamente da esquina, abriga o Museu de Ciências Naturais Carlos Ritter. Na escala 1:100, nos moldes mais próximos de maquetes tradicionais (C), integra-se outra camada de informação sobre a distribuição dos cômodos nos diferentes níveis que compõem a edificação. São disponibilizados mapas táteis portáteis, relativos as plantas baixas, removíveis da maquete em um sistema de gavetas (D), apoiando-se no método configurado em Sperling et al. (2015). Este tipo de produção exemplifica uma das atividades realizadas no âmbito da curricularização da extensão, efetivada recentemente na FAUrb/UFPel. Este tipo de recurso encontra-se já disponível também no
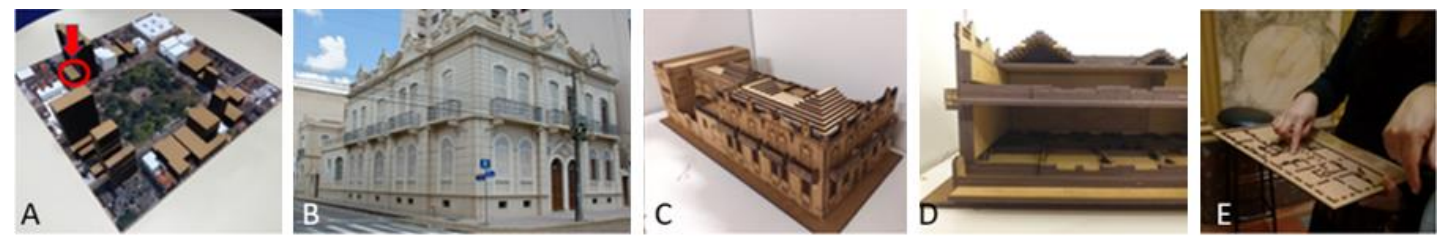

Figura 8: A) Casas Gêmeas, escala 1:500; B e C) foto e maquete, 1:100; E) mapas táteis do Museu do Doce

Fonte: Boyle et al. (2019)
Museu do Doce (E), sendo utilizado para ser validado pelos visitantes, conforme descrito em Boyle et al. (2019).

A linguagem arquitetônica dos demais edifícios do entorno (não inventariados/ patrimoniados), está sendo representada pela aplicação de texturas, configuradas por fotografias retificadas de suas fachadas, sobre os modelos simplificados (em MDF na maquete do espaço urbano) na escala 1:500. E, paulatinamente, no ritmo das atividades de investigação,

Gestão \& Tecnologia de Projetos 
ensino e extensão, o método AGI também será aplicado, para oferecer uma infraestrutura que facilite a compreensão do todo deste entorno.

\section{A PRODUÇÃO DE SENTIDOS}

Os resultados esperados para este estudo referem-se à reflexão sobre os sentidos atribuídos ao processo, de representação do patrimônio, aqui descrito. Trata-se, mais especificamente, de problematizar o emprego das tecnologias de fabricação digital, utilizadas para produção dos modelos que estruturam o método da adição gradual da informação. Como anunciado anteriormente, utiliza-se para esta problematização a teoria da escalada da abstração de Vilém Flusser (1998), observando-se assim a relação das variáveis dimensionais dos modelos empregados com os níveis de abstração necessários para produzi-los e/ou compreendê-los. Esta produção refere-se ao ato de representar, nos termos piagetianos, de construção de conhecimento. A interação com o objeto (paisagem urbana) se dá inicialmente na vivência do espaço, no tridimensional, proposta a ser intensificada por um roteiro turístico com o apoio de um conjunto de representações caracterizados como recursos assistivos. Nesta primeira interação, pode haver o envolvimento de vários sentidos (visão, audição, olfato e tato), incluindo a proposta de complementação da informação para as pessoas com deficiência visual, tratando de exigir um nível de abstração menor possível em termos comunicacionais em relação à forma desta paisagem.

A representação pelo desenho (bidimensional), nos termos flusserianos, ao eliminar uma das dimensões, exige um maior nível de abstração. 0 desenho a mão, produzido por estudantes de arquitetura e utilizado no folder de referência, foi substituído, junto ao método AGI, pelo exercício de vetorização de imagens (processo digital). Esta vetorização se faz necessária para o desenvolvimento dos modelos tridimensionais dos elementos que compõem as fachadas dos edifícios, sobre as fotografias retificadas ou sobre a visualização ortogonal das nuvens de pontos, especialmente para a produção de desenhos para o corte a laser. Este processo abstracional/interacional envolve uma maior atenção sobre a forma e seu significado no âmbito das linguagens de arquitetura envolvidas, para que as imagens mentais provocadas pelo tato auxiliem na apropriação do conhecimento a ser construído por cada usuário. 0 exercício de reconhecer e traduzir as representações unidimensionais (descrições textuais das edificações), por parte da equipe de mediação exige a apropriação efetiva do discurso sobre o objeto representado como um todo (paisagem urbana). Os depoimentos orais dos usuários têm demonstrado também tal apropriação, embora não tenha sido oportunizada a expressão escrita, a qual terá que envolver o sistema estruturado pelo pedagogo francês Louis Braille (1809-1852), sistema tátil formado por pequenos pontos salientes para serem decifrados pela ponta dos dedos. Destaca-se que a Escola Louis Braille, envolvida nas ações, tem adicionado paulatinamente este sistema de escrita ao recurso. A associação do discurso ao modelo tem se constituído como uma ação lúdica de perceber tatilmente a narrativa traduzida em forma arquitetônica. Por fim, compreende-se o uso de imagens técnicas, incluindo a fotografia, a fotogrametria digital, o escaneamento 3D a laser, a modelagem geométrica e visual e a fabricação digital, todos computáveis, envolvendo um alto nível de abstração. Para o contexto acadêmico, por meio da trajetória de aprendizado proposta, cada uma delas está guiada por uma consciente intenção de uso e controle de um tipo específico de produção. Desta maneira, não se trata de uma prática representacional que atribui autonomia ao aparelho. Ao contrário, foge da postura "proletária" associada ao tipo de relação a ser evitada, do usuário com tais tecnologias, alertada por Flusser (1998).

As informações contidas no folder de referência, bi e unidimensionais (desenhos e textos) foram assim ampliadas, partindo e retornando à tridimensionalidade, utilizando-se da trajetória de uso das imagens técnicas, nulodimensionais. 
Adiciona-se ainda uma reflexão sobre a oportunidade de incremento à infraestrutura de um turismo ubíquo. Refere-se à possibilidade, frente à popularização das tecnologias de impressão 3D, de disponibilização dos arquivos digitais com acesso aberto para a obtenção dos modelos táteis desde qualquer lugar. Isto poderá contrapor à problemática de tempo necessário para experenciar as diferentes camadas de informação produzidas. Deve-se ter em conta que para se adquirir informação suficiente, por meio do tato, capaz de contribuir para a construção da imagem mental, necessita-se de mais tempo. Este modelo, sendo ajustado para outras escalas e tecnologias de impressão 3D, pode informar um grau de precisão geométrica maior, especialmente sobre a ornamentação das fachadas. Assim o usuário aplicaria o método AGI, compondo sua própria narrativa, a partir da impressão em diferentes escalas, podendo particularizar elementos. Isto vem ao encontro do questionamento sobre a simplificação para a escala de 1:500. Esta escala inviabiliza discernir todos os elementos de fachada pelo tato, mas, mesmo considerando os limites da tecnologia (precisão de impressão) consegue informar para a percepção visual, contemplando assim o propósito de desenho universal. Já nos últimos processos de representação, os limites passaram a ser a habilidade de quem representa e/ou as informações precisas sobre a geometria, por envolver formas complexas.

\section{CONSIDERAÇÕES FINAIS}

O processo de representação aqui referido, por um lado, constitui-se como infraestrutura para promover a inclusão cultural de pessoas com deficiências visuais. Por outro, como oportunidade para promover uma formação profissional em arquitetura, sensível e apta ao Desenho Universal e à interação com a sociedade, tendo em vista a experiência de caráter extensionista.

O exercício de realizar uma leitura dos meios de comunicação envolvidos em todo o processo, apoiado nas reflexões flusserianas tem induzido ao estabelecimento de um ambiente acadêmico reflexivo especialmente quanto à postura de uso das tecnologias digitais de representação. E, mais do que isto, desloca o objetivo didático centrado no tempo tecnológico atual para a construção de uma postura atenta a qualquer tempo.

Partiu-se de um resultado concreto, o "maquetão", como tem sido tratado no contexto do estudo, avançando-se para resultados essencialmente qualitativos. Estes expressados pelo afeto das pessoas que vivenciam a experiência, tanto por parte dos usuários dos modelos como por parte da equipe de desenvolvimento das representações. Tal experiência, a todo momento transita pelos diferentes níveis de abstração. As representações, produzidas por fabricação digital, estão carregadas de sentidos: social, formativo, cultural e profissional. Podem ser reproduzidas em série, pelos aparelhos, entretanto, são os momentos de interação com estas representações que possibilitam a transgressão ou a criatividade para avançar com a inclusão cultural e com o aperfeiçoamento do processo formativo para o projeto. Desta interação é possível que surjam outras representações ainda impensadas, avançando em todo o processo comunicacional.

\section{Agradecimentos}

À equipe do GEGRADI/UFPel, ao Rafael Eslabão que garantiu o funcionamento das máquinas e aos órgãos financiadores (FINEP, FAPERGS, CAPES, PROEXT/UFPel). 


\section{Referências Bibliográficas}

BORDA, A.; VEIGA, M.; NICOLETTI, L.; MICHELON, F. Descrição de fotografias a partir de modelos táteis: ensaios didáticos e tecnológicos. In: SEMINÁRIO INTERNACIONAL MUSEOGRAFIA E ARQUITETURA DE MUSEUS, 3, 2012, Rio de Janeiro. Conservação e Técnicas sensoriais. Rio de Janeiro: UFRJ, 2012. v. 1. p. 01-15

BORDA, A.; SILVEIRA, D.; MEDINA, A.; VECCHIA, L. Pontos (de vista) sobre o patrimônio: entre o escaneamento e a fotogrametria In: XX CONGRESO INTERNACIONAL DE LA SOCIEDAD IBEROAMERICANA DE GRÁfICA DIGITAL, Buenos Aires. Blucher Design Proceedings. São Paulo: Editora Blucher, 2016. v.3. p.651-556

BORDA, A. Tactile narratives about an architecture's ornaments In: XXI CONGRESO INTERNACIONAL DE LA SOCIEDAD IBEROAMERICANA DE GRÁFICA DIGITAL, 2017, Concepción. Blucher Design Proceedings. São Paulo: Editora Blucher, 2017. v.3. p.439-444

BORDA, A.; NUNES, C.; GOULART, S.; HARTER, B. Impressions of a touristic route: between the nulldimensional and the three-dimensional In: XXII CONGRESSO INTERNACIONAL DA SOCIEDADE IBEROAMERICANA DE GRÁFICA DIGITAL, 2018, São Carlos. Blucher Design Proceedings. São Paulo: Editora Blucher, 2018. p.345-350

BOYLE, L.; TEIXEIRA, A.; SANTOS, E.; KNORR, I.; BRAGA, K.; BORDA, A. Representações das Casas Gêmeas por tecnologias de fabricação digital: uma contribuição para o acervo tátil do entorno da praça Cel. Pedro Osório, Pelotas In: CONGRESSO DE EXTENSÃO E CULTURA DA UFPEL, 6, 2019, Pelotas. Tecnologia e Produção. Pelotas: UFPel, 2019. v. 1. p. 109-112

COOK, A.; POLGAR, J. Cook and Hussey's assistive technologies: principles and practice. 3. ed. Philadelphia: Mosby Elsevier, 2008.

DALLA VECCHIA, L.; BORDA, A.; PIRES, J.; VEIGA, M.; VASCONSELOS, T.; BORGES, L. Tactile models of elements of architectural heritage: from the building scale to the detail. In: CAAD FUTURES CONFERENCE, 16, 2015, São Paulo. The next city - New technologies and the future of the built environment. p. 434-446.

FLUSSER, V. Ensaio sobre a Fotografia: para uma filosofia da técnica. 1 ed. Lisboa: Relógio d' Água, 1998.

FREIRE, P. Extensão ou comunicação? Rio de Janeiro: Paz e Terra, 2013.

GUTIERREZ, E. Negros, charqueadas e olarias: um estudo sobre o espaço pelotense. Pelotas: Ed. Universitária, 1993.

GUTIERREZ, E. O monte bonito cobriu-se de sangue: história do sítio charqueador Pelotense. In: SEMINÁRIO DE PATRIMÔNIO AGROINDUSTRIAL LUGARES DE MEMÓRIA, 2, 2010, São Carlos. 0 patrimônio material da agroindústria: arquitetura, espaços de produção e configuração espacial. p. $1-14$.

MICHELON, F. (org.). Entre o sal e o açúcar: o doce através dos sentidos: catálogo do projeto Os Museus do Conhecimento para Todos. Bagé: Bühring, 2016.

ORNSTEIN, S. (org.). Desenho universal: caminhos da acessibilidade no Brasil. São Paulo: Annablume, 2010.

PALLASMAA, J. Os olhos da pele: a arquitetura e os sentidos. Porto Alegre: Bookman, 2011. 
PEREIRA, C; HEITOR, T; HEYLIGHEN, A. Exploring invisibility through multisensory spatial research methods. In: EUROPEAN CONGRESS OF QUALITATIVE INQUIRY, 2, 2017, Leuven. Proceedings Quality and Reflexivity in Qualitative Inquiry. Leuven: KU Leuven NQRL, 2017. p. 9-18.

PIAGET, J. Epistemologia Genética. São Paulo: Martins Fontes, 2002.

SANTOS, C. Ecletismo na fronteira meridional do Brasil: 1870-1931. Orientadora: Esterzilda Berenstein de Azevedo. 2007. Tese (Doutorado em Arquitetura e Urbanismo) - Faculdade de Arquitetura e Urbanismo, UFBA, Salvador, 2007.

SILVA, D.; COSTA, C.; RIGHI, R.; COSTA, H. UbitourAR: A ubiquitous tourism model based on augmented reality. Journal of Applied Computing Research. São Leopoldo, v. 4, n. 1, p. 1-12. 2014.

SPERLING, D.; VANDIER, I.; SCHEEREN, R. Sentir o espaço: projeto com modelos táteis. In: CONGRESSO DA SOCIEDADE IBERO-AMERICANA DE GRÁFICA DIGITAL, 19, 2015, Santa Catarina. Digital manufacturing \& rapid prototyping. v.2, n.3. p. 108-1

Adriane Borda Almeida da Silva

adribord@hotmail.com

Cristiane dos Santos Nunes cristiane.nunes@outlook.com

Stefani Curth Goulart stefanigoulart@outlook.com

Bethina Harter Silva bethinaharters@hotmail.com 